\title{
Desempenho, morfometria de órgãos e histologia intestinal de suínos na fase de terminação tardia alimentados com cana-de-açúcar
}

\author{
Performance, organs morphometry and intestinal histology of pigs in the late finishing \\ fed cane sugar
}

\author{
AROUCA, Cláudio Luiz Correa ${ }^{1}$; MACIEL, Mônica Patrícia ${ }^{1 *}$; AIURA, Felipe \\ Shindy $^{1}$; BARBOSA, Marcília Medrado ${ }^{1}$; BOTELHO, Luiz Fernando Rocha ${ }^{1}$; \\ PEREIRA, Fernando Matos ${ }^{2}$; PEREIRA, Fabiano Matos ${ }^{2}$
}

\footnotetext{
${ }^{1}$ Universidade Estadual de Montes Claros, Departamento de Ciências Agrárias, Jarnáuba, Minas Gerais, Brasil.

${ }^{2}$ Instituto Federal de Educação, Ciência e Tecnologia do Norte de Minas Gerais, Coordenadoria Geral de Produção e Pesquisa, Seção de Zootecnia II, Salinas, Minas Gerais, Brasil.

*Endereço para correspondência: monicapatriciamaciel@yahoo.com.br
}

\section{RESUMO}

Objetivou-se avaliar o desempenho, morfometria de órgãos e histologia intestinal de suínos, em fase de terminação tardia, alimentados com cana-deaçúcar em substituição ao milho. Foram utilizados 36 suínos machos, castrados, com peso inicial médio de $103,86 \mathrm{~kg}$, idade média de 153,5 dias e peso final médio de $126,89 \mathrm{~kg}$ e idade média final de 179,5 dias. Utilizou-se delineamento experimental em blocos casualizados, com tratamentos repetidos, distribuídos em: 3 tratamentos, 3 blocos e 2 repetições de tratamento por bloco, a perfazer 6 repetições. Os tratamentos utilizados foram: ração convencional; ração convencional, com substituição de $30 \%$ do milho pela cana-de-açúcar e; ração convencional, com substituição de $30 \%$ do milho pela cana-de-açúcar e com os nutrientes corrigidos, exceto a energia. Os suínos que consumiram dietas com cana-deaçúcar, em substituição parcial ao milho, ingeriram mais ração e tiveram pior conversão alimentar, porém não houve diferença no ganho de peso observado nos animais submetidos aos tratamentos avaliados. $\mathrm{O}$ custo de alimentação por $\mathrm{kg}$ de suíno produzido foi menor com a utilização de $30 \%$ de cana-de-açúcar em substituição ao milho, com correção dos nutrientes. Os tratamentos não influenciaram a morfometria dos órgãos. Observou-se maior altura de vilosidades no duodeno, jejuno e íleo e maior profundidade de cripta no duodeno e jejuno dos animais, alimentados com rações composta de cana-deaçúcar. Em suínos na fase de terminação tardia, recomenda-se a utilização de $30 \%$ de cana-de- açúcar integral em substituição ao milho, com correção dos nutrientes, pois promove melhor eficiência econômica.

Palavras-chave: alimento alternativo, cana-deaçúcar, fibra, histomorfologia, suinocultura.

\section{SUMMARY}

This study aimed to evaluate the performance, organ morphology and intestinal histology of growing pigs in late termination, fed sugar cane instead of corn. Thirty six barrows with approximately 153.5 days of age were used, with an average initial weight of $103.86 \mathrm{~kg}$ and final mean weight and age of $126.89 \mathrm{~kg}$ and 179.5 days. The experimental design was a randomized block with repeated treatments, with 3 treatments, 3 blocks and 2 replicates per treatment block, completing 6 repetitions. The treatments were: conventional diet; conventional diet, with $30 \%$ replacement of corn by sugar cane, and conventional diet, with $30 \%$ replacement of corn by sugar cane and the corrected nutrients except energy. Pigs fed diets with sugar cane instead of corn partially consumed more feed and had lower feed efficiency, but there was no difference in weight gain observed in animals subjected to the treatments. The cost of feed per $\mathrm{kg}$ of pig produced was lower with the use of $30 \%$ sugar cane instead of corn, with the correct nutrients. Treatments did not affect the morphology of organs. There was greater villi height in the duodenum, jejunum and ileum and 
increased crypt depth in the duodenum and jejunum of animals fed diets containing sugar cane. In pigs in the late finishing fase is recommended to use $30 \%$ of whole sugar cane replacement of corn with the correct nutrients, it promotes better economic efficiency.

Keywords: alternative food, fiber, histomorphology, pig farming.

\section{INTRODUÇÃO}

Atualmente, a busca por alimentos alternativos para suínos, sobretudo, para as fases de crescimento e terminação, que não afetem os índices zootécnicos e a custos mais baixos, tem sido uma preocupação constante (NERY et al., 2010). Nas condições brasileiras, a fração energética das rações para animais não ruminantes tem como base o milho e o farelo de soja. A demanda nacional por esses insumos, para a alimentação animal, é superior à produção e à disponibilidade verificada nos últimos anos. Dessa forma, pesquisas direcionadas a produtos $\mathrm{e}$ subprodutos alternativos tornam-se imprescindíveis, principalmente, com aqueles ingredientes disponíveis para os animais durante todo o período de entressafra dos convencionais ou durante todo o ano.

Segundo Furtado (2002), algumas das vantagens da utilização da cana-deaçúcar integral para suínos são: o baixo preço do alimento, o menor índice de distúrbios respiratórios dos animais, em função da diminuição da pulverulência da dieta, a redução da dependência das oscilações do preço do milho e a menor importação de grãos para o sistema produtivo. Por outro lado, segundo o mesmo autor, existem fatores negativos, como a composição química da cana, caracterizada como alta em fibra e baixa em proteína, o que pode levar a um menor ganho de peso e maior consumo da dieta e, consequentemente, a uma maior idade de abate.

Apesar de a cana-de-açúcar integral conter alto teor de fibra bruta, suínos adultos apresentam trato gastrintestinal mais desenvolvido, o que propicia a atuação da microbiota do intestino grosso sobre a fibra, o que produz ácidos graxos voláteis possíveis de serem absorvidos e utilizados como fonte de energia pelos animais. Por outro lado, o teor de fibra dietética também pode diminuir a digestibilidade fecal aparente de outros nutrientes dietéticos, tais como proteína bruta e gordura (NOBLET \& Le GOFF, 2001), mas esse efeito tem sido menor em suínos mais pesados e porcas (NOBLET \& VAN MILGEN, 2004).

Cordeiro et al. (2009) substituíram parte da ração de suínos, em crescimento, por $15 \%$ e $30 \%$ de cana-de-açúcar integral desintegrada e concluíram que o melhor desempenho foi alcançado com a substituição de $15 \%$, embora $30 \%$ tenha propiciado melhor eficiência econômica. Diante do exposto, objetivou-se avaliar o desempenho, morfometria de órgãos e histologia intestinal de suínos machos, castrados, na fase de terminação tardia, que recebiam cana-de-açúcar integral em substituição ao milho.

\section{MATERIAL E MÉTODOS}

O experimento teve duração de 26 dias e foi conduzido na granja de suínos do Instituto Federal de Educação, Ciência e Tecnologia do Norte de Minas Gerais/Campus de Salinas, nos meses de julho e agosto de 2010. Foram utilizados 36 suínos machos, castrados, híbridos comerciais na terminação tardia, que corresponde à fase após a terminação tradicional, dos 100 aos $120 \mathrm{~kg}$. Os animais eram provenientes 
do cruzamento industrial AGPIC $337 \mathrm{x}$ CAMBOROUGH 23, com peso inicial médio de 103,86kg, idade média de 153,5 dias e peso final médio de $126,89 \mathrm{~kg}$ e idade média de 179,5 dias.

Os animais foram alojados em galpão de terminação, em baias $(2,5 \times 5,5 \mathrm{~m})$, que continham comedouro de alvenaria e bebedouro tipo chupeta e onde se disponibilizavam ração e água à vontade. A unidade experimental foi de 2 animais por baia. Utilizou-se delineamento experimental em blocos casualizados, com tratamentos repetidos, distribuídos em 3 tratamentos, 3 blocos e 2 repetições de tratamento por bloco, a perfazer 6 repetições. Os tratamentos foram compostos por 3 rações: 1) ração convencional; 2) ração convencional, com substituição de $30 \%$ do milho pela cana-de-açúcar e 3) ração convencional, com substituição de $30 \%$ do milho pela cana-de-açúcar e com os nutrientes corrigidos, exceto a energia.

Diariamente, a cana era triturada em um desintegrador de forragens, peneirada manualmente e misturada, na quantidade predeterminada, às rações dos tratamentos 2 e 3. As rações foram formuladas para atender às exigências nutricionais mínimas para suínos de alto potencial genético e desempenho superior, conforme recomendações de Rostagno et al. (2005). A composição percentual e os valores calculados das rações experimentais encontram-se na Tabela 1. As variáveis de desempenho analisadas foram ganho de peso diário, consumo de ração diário e conversão alimentar. $\mathrm{O}$ ganho de peso diário, no período, foi mensurado através da pesagem individual de cada animal, dividido pelos dias de experimento (26 dias). $\mathrm{O}$ consumo de ração diário foi determinado pela diferença entre a quantidade de ração fornecida e a sobra e desperdícios diários. A conversão alimentar foi calculada através da relação entre o consumo de ração e o ganho de peso dos animais.

Ao término do período experimental, um animal de cada unidade experimental foi submetido a jejum alimentar de 24 horas e abatido por dessensibilização e sangramento. Após o abate, procedeu-se à sangria nos grandes vasos do pescoço, escalda de imersão em água entre 60 e $65^{\circ} \mathrm{C}$ por 5 minutos, depilação manual, evisceração, retirada dos órgãos e divisão da carcaça. Foram colhidos dados referentes ao peso dos órgãos digestórios (estômago, intestino delgado, intestino grosso), cheios e vazios, e ainda do pâncreas, fígado, baço, rins, pulmões e coração. Cada órgão foi separado e pesado individualmente. Após a pesagem do intestino delgado, foram coletados segmentos de cerca de $3 \mathrm{~cm}$ do duodeno, jejuno e íleo, lavados com água destilada e acondicionados em recipientes devidamente identificados, que continham líquido de Bouin para fixação do material. Após 24 horas, o material foi lavado e conservado em álcool $70 \%$.

Posteriormente, as amostras foram desidratadas, em série crescente de alcoóis. Após a desidratação, foram cortadas, diafanizadas em benzol e incluídas em parafina para se obter cortes longitudinais da mucosa intestinal. Foi feita a microtomia dos blocos, da qual obtiveram-se cortes de $5 \mu \mathrm{m}$ de espessura. Os cortes foram corados com a técnica de hematoxilinaeosina. Com as lâminas prontas, foram selecionadas e medidas 10 criptas e 10 vilosidades, em diferentes regiões dos cortes (regiões medianas do duodeno, jejuno e íleo), para obtenção das medidas de altura de vilosidades e profundidade de criptas, cuja unidade adotada foi o micrometro $(\mu \mathrm{m})$. 
Rev. Bras. Saúde Prod. Anim., Salvador, v.13, n.4, p.1074-1083 out./dez., 2012 http://www.rbspa.ufba.br ISSN 15199940

Tabela 1. Composição percentual e os valores calculados das rações experimentais

\begin{tabular}{|c|c|c|c|}
\hline \multirow{2}{*}{ Ingrediente $(\%)$} & \multicolumn{3}{|c|}{ Tratamento } \\
\hline & 1 & 2 & 3 \\
\hline Milho & 82,63 & 57,83 & 55,47 \\
\hline Farelo de soja & 14,65 & 14,65 & 18,43 \\
\hline Fosfato bicálcico & 0,82 & 0,82 & 0,82 \\
\hline Calcário calcítico & 0,47 & 0,47 & 0,33 \\
\hline Sal comum & 0,30 & 0,30 & 0,28 \\
\hline Premix vitamínico-mineral ${ }^{1}$ & 0,50 & 0,50 & 0,50 \\
\hline L-Lisina & 0,18 & 0,18 & 0,12 \\
\hline DL-Metionina & - & - & 0,02 \\
\hline Premix antibiótico ${ }^{2}$ & 0,10 & 0,10 & 0,10 \\
\hline Adsorvente de micotoxina & 0,15 & 0,15 & 0,15 \\
\hline Óleo de soja & 0,20 & 0,20 & - \\
\hline Cana-de-açúcar integral & - & 24,80 & 23,78 \\
\hline Total & 100,00 & 100,00 & 100,00 \\
\hline \multicolumn{4}{|l|}{ Valores calculados } \\
\hline Energia Metabolizável suínos (Mcal/kg) & 3,2362 & - & - \\
\hline Proteína Bruta (\%) & 13,925 & 12,479 & 13,928 \\
\hline Cálcio $(\%)$ & 0,4555 & 0,4977 & 0,4528 \\
\hline Fósforo total $(\%)$ & 0,4362 & 0,3921 & 0,4082 \\
\hline Fósforo disponível (\%) & 0,2456 & 0,2407 & 0,2450 \\
\hline Fibra Bruta $(\%)$ & 2,4786 & 8,5744 & 8,4816 \\
\hline Lisina total $(\%)$ & 0,7550 & 0,6930 & 0,7490 \\
\hline Lisina digestível suínos (\%) & 0,6641 & 0,6148 & 0,6605 \\
\hline Met. + Cistina total $(\%)$ & 0,4923 & 0,4000 & 0,4564 \\
\hline Met. + Cistina digestível suínos (\%) & 0,4422 & 0,3596 & 0,4115 \\
\hline Metionina total $(\%)$ & 0,2357 & 0,1935 & 0,2309 \\
\hline Metionina digestível suínos (\%) & 0,2184 & 0,1794 & 0,2142 \\
\hline Treonina total $(\%)$ & 0,5334 & 0,4516 & 0,5111 \\
\hline Treonina digestível suínos (\%) & 0,4371 & 0,3726 & 0,4232 \\
\hline Triptofano total $(\%)$ & 0,1452 & 0,1303 & 0,1537 \\
\hline Triptofano digestível suínos (\%) & 0,1254 & 0,1132 & 0,1332 \\
\hline Sódio $(\%)$ & 0,1533 & 0,1566 & 0,1501 \\
\hline
\end{tabular}

${ }^{\mathrm{T}}$ Níveis de garantia (por kg do produto): Vitamina A-532.000 UI; Vitamina D3- 112.000 UI; Vitamina E2.100mg; Vitamina K3-280mg; Tiamina (B1)-138mg; Riboflavina (B2)-490mg; Piridoxina (B6)- 97mg; Vitamina B12 - 1.680mcg; Niacina - 2.800mg; Ácido Fólico - 70mg; Pantotenato de Cálcio - 1.680mg; Colina - 15.000mg; Cobalto - 100mg; Cobre - 3.000mg; Ferro - 12.000mg; Iodo - 200mg; Manganês $6.200 \mathrm{mg}$; Selênio - 42mg; Zinco - 24.000mg.

${ }^{2}$ Níveis de garantia (por Kg do produto): fosfato de tilosina - 100g; sulfametazina - 100g.

Os resultados relativos ao desempenho, morfometria de órgãos e histologia intestinal foram submetidos à análise de variância, para a qual utilizou-se o pacote computacional SISVAR. Os tratamentos foram comparados pelo teste de Tukey, a $5 \%$ de probabilidade. Foram realizadas as seguintes análises de custo: custo/kg de ração, custo/dia de consumo e o custo da alimentação/kg de suíno produzido. Os preços dos 
ingredientes das rações foram obtidos em fevereiro de 2012. Em seguida, foi calculado $o$ índice de eficiência econômica, determinado pela razão entre o menor custo médio e o custo médio do tratamento considerado, multiplicado por cem.

\section{RESULTADOS E DISCUSSÃO}

Não houve diferença $(P>0,05)$ entre o ganho de peso dos animais que receberam as rações com cana e a convencional (Tabela 2).

Tabela 2. Ganho de peso diário (GPD), consumo de ração diário (CRD) e conversão alimentar (CA) de suínos em fase de terminação tardia alimentados com dietas com diferentes níveis de cana-de-açúcar em substituição parcial ao milho*

\begin{tabular}{lcccc}
\hline \multirow{2}{*}{ Variável } & \multicolumn{3}{c}{ Tratamento } & CV \\
\cline { 2 - 4 } & 1 & 2 & 3 & $(\%)$ \\
\hline GPD $(\mathrm{kg})$ & 0,894 & 0,848 & 0,931 & 13,57 \\
CRD $(\mathrm{kg})$ & $3,185^{\mathrm{b}}$ & $3,656^{\mathrm{a}}$ & $3,798^{\mathrm{a}}$ & 6,76 \\
$\mathrm{CA}(\mathrm{kg} / \mathrm{kg})$ & $3,69^{\mathrm{a}}$ & $4,66^{\mathrm{b}}$ & $4,22^{\mathrm{b}}$ & 13,24 \\
\hline
\end{tabular}

*Médias seguidas pela mesma letra nas linhas não diferem entre si pelo teste Tukey $(\mathrm{P}<0,05)$.

1- ração convencional; 2- ração convencional, com substituição de $30 \%$ do milho pela cana-de-açúcar e 3- ração convencional, com substituição de $30 \%$ do milho pela cana-de-açúcar e com os nutrientes corrigidos, exceto a energia.

$\mathrm{CV}=$ coeficiente de variação.

Wilfart et al. (2007) também não observaram diferenças entre o ganho de peso diário de suínos, em crescimento, alimentados com dietas formadas por 17,21 e $27 \%$ de fibra bruta. Do mesmo modo, Gomes et al. (2007), ao fornecerem uma ração, com incremento de $8 \%$ de fibra (obtido pelo acréscimo de $10 \%$ de feno), não verificaram diferenças no ganho de peso de suínos em terminação. Os autores comentam que os suínos, em particular os animais na fase adulta, como na terminação e pós-terminação (151-185 dias), mesmo quando alimentados com elevados níveis de fibra dietética, são capazes de manter o ganho de peso em índices adequados, devido à capacidade de elevação do consumo, como tentativa de manter estável o nível de energia digestível ingerida.

$\mathrm{O}$ consumo de ração diário foi menor $(\mathrm{P}<0,05)$ para os animais que receberam a dieta convencional, quando comparados aos que receberam as dietas com canade-açúcar. O maior consumo, observado nos animais que receberam as rações com cana, talvez, deve-se ao aumento da palatabilidade da dieta, em função dos elevados níveis de sacarose e glicose, presentes na cana-de-açúcar e em função do efeito laxativo desencadeado pela fibra, que eleva a taxa de passagem do alimento no trato digestório e, consequentemente, aumenta a capacidade de consumo dos animais (CASTRO JÚNIOR et al., 2005).

Cordeiro et al. (2009) também observaram aumento do consumo de leitões, em crescimento, que receberam cana-de-açúcar integral na dieta. Os autores atribuíram esse resultado ao menor teor de energia digestível, obtido quando substituíram parte da ração por cana-de-açúcar em 30\%, o que implicou em maior consumo dos animais para que suprissem as necessidades em energia. $\mathrm{O}$ mesmo pode ter ocorrido nesta pesquisa, de modo a haver a necessidade de maior consumo de ração por parte dos suínos que receberam ração com cana.

Os tratamentos, com adição de cana-deaçúcar, influenciaram negativamente $(\mathrm{P}<0,05)$ a conversão alimentar dos animais (Tabela 2). É sabido, que essa conversão é calculada pelo quociente 
Segundo Hansen et al. (1992), os suínos apresentam aumento do peso, volume e capacidade do trato gastrointestinal, quando alimentados com rações fibrosas, o que estaria em consonância com possíveis alterações na motilidade e morfologia do trato gastrointestinal desses animais. Em concordância com essa afirmativa, Gomes et al. (2006) observaram aumento apenas do trato gastrintestinal de suínos que consumiram ração fibrosa ( $10 \%$ de feno de alfafa) e ressaltaram que, para os demais órgãos, os pesos foram similares. Watanabe (2007) observou maior peso de estômago, cólon e ceco de suínos que receberam níveis crescentes de polpa cítrica na ração. O maior conteúdo de fibra, nas dietas com polpa cítrica, contribuiu para o aumento da produção de secreção gástrica e a maior fermentação no intestino grosso, a acarretar maior peso dos órgãos. Todavia, Vieira et al. (2006) também não observaram efeito da substituição de parte da ração de fêmeas suínas, em crescimento, por até $50 \%$ de bagaço de cevada.

$\mathrm{O}$ fato de aqui não serem registradas diferenças, pode ser devido ao período curto de duração do experimento (26 dias), o qual pode não ter sido suficiente para que houvesse alterações no peso dos órgãos. A altura das vilosidades no duodeno, jejuno e íleo e a profundidade de cripta no duodeno e jejuno dos animais alimentados com cana-deaçúcar foram maiores $(\mathrm{P}<0,05)$ do que a dos animais alimentados com a ração convencional (Tabela 4).

Tabela 4. Altura das vilosidades, profundidade de cripta e relação vilo:cripta de suínos, em fase de terminação tardia, alimentados com dietas com diferentes níveis de cana-de-açúcar, em substituição parcial ao milho*

\begin{tabular}{|c|c|c|c|c|}
\hline \multirow{3}{*}{ Variável } & \multicolumn{3}{|c|}{ Tratamento } & \multirow[b]{2}{*}{$\mathrm{CV}(\%)$} \\
\hline & 1 & 2 & 3 & \\
\hline & \multicolumn{3}{|c|}{ Altura de vilosidades $(\mu \mathrm{m})$} & \\
\hline Duodeno & $501^{b}$ & $598^{\mathrm{a}}$ & $600^{\mathrm{a}}$ & 15,53 \\
\hline Jejuno & $529^{\mathrm{b}}$ & $585^{\mathrm{a}}$ & $596^{\mathrm{a}}$ & 23,72 \\
\hline Íleo & $510^{\mathrm{b}}$ & $596^{\mathrm{a}}$ & $661^{\mathrm{a}}$ & 12,34 \\
\hline \multicolumn{5}{|c|}{ Profundidade de cripta $(\mu \mathrm{m})$} \\
\hline Duodeno & $354^{\mathrm{b}}$ & $396^{\mathrm{a}}$ & $393^{\mathrm{a}}$ & 11,50 \\
\hline Jejuno & $382^{\mathrm{b}}$ & $398^{\mathrm{a}}$ & $400^{\mathrm{a}}$ & 15,24 \\
\hline Íleo & $363^{\mathrm{a}}$ & $390^{\mathrm{a}}$ & $382^{\mathrm{a}}$ & 25,40 \\
\hline \multicolumn{5}{|c|}{ Relação vilo:cripta $(\mu \mathrm{m})$} \\
\hline Duodeno & 1,41 & 1,49 & 1,52 & 18,15 \\
\hline Jejuno & 1,38 & 1,43 & 1,50 & 19,42 \\
\hline Íleo & 1,40 & 1,54 & 1,72 & 21,14 \\
\hline
\end{tabular}

"Médias seguidas pela mesma letra nas linhas não diferem entre si pelo teste Tukey $(\mathrm{P}<0,05)$.

1- ração convencional; 2- ração convencional, com substituição de $30 \%$ do milho pela cana-de-açúcar e 3ração convencional, com substituição de $30 \%$ do milho pela cana-de-açúcar e com os nutrientes corrigidos, exceto a energia.

$\mathrm{CV}=$ coeficiente de variação.

Alimentos fibrosos, como a cana-deaçúcar estimulam a taxa de passagem pelo trato gastrintestinal, a produção de enzimas secretadas pelo intestino delgado para a digestão e renovação celular (LI et al., 1990). Alguns autores 
já observaram alterações na mucosa gastrintestinal com a utilização de alimentos fibrosos na dieta (HEDEMANN et al., 2006; ARRUDA et al., 2008).

A profundidade da cripta é um indicativo da capacidade compensatória ou hiperplasia das células epiteliais, em virtude de um maior nível de agressão à estrutura morfológica da mucosa intestinal causada pelas dietas. A redução da altura das vilosidades, em decorrência do aumento na taxa de descamação epitelial, pode ser resultante do incremento da profundidade da cripta para assegurar a adequada taxa de "turnover" celular e garantir a reposição das perdas de células da região apical das vilosidades (ARAÚJO et al., 2006; OETTING et al., 2006). Isso permite inferir que quanto maior a relação altura de vilosidades (AV): profundidade de criptas (PC), melhor a absorção de nutrientes e menores as perdas energéticas com a renovação celular.

Não foram observadas diferenças entre os tratamentos na relação AV:PC. Embora se tenha observado maiores PC nas dietas com cana (o que sugeriria um maior nível de agressão à estrutura celular da mucosa intestinal), a altura das vilosidades não foi prejudicada, o que pode ter refletido em um bom aproveitamento dos nutrientes pelos animais e resultado em um ganho de peso não diferente dos animais não alimentados com cana-de-açúcar.

$\mathrm{O}$ custo por $\mathrm{kg}$ de ração e o custo/dia de consumo foram menores nos tratamentos nos quais foi substituído o milho pela cana (Tabela 5). Isso indica que, apesar de os suínos terem apresentado maior consumo das rações com cana, seu uso ainda se mostra vantajoso, pois refletiu em ganho de peso semelhante ao convencional, porém com menor custo.

Tabela 5. Custo por kg de ração, custo por dia de consumo, custo da alimentação por kg de suíno produzido e índice de eficiência econômica da criação de suínos, em fase de terminação tardia, alimentados com dietas com diferentes níveis de cana-de-açúcar, em substituição parcial ao milho*

\begin{tabular}{lccc}
\hline \multirow{2}{*}{ Variável } & \multicolumn{3}{c}{ Tratamento } \\
\cline { 2 - 4 } & 1 & 2 & 3 \\
\hline Custo/kg de ração (R\$) & 0,75 & 0,61 & 0,62 \\
Custo/dia de consumo (R\$) & 2,38 & 2,24 & 2,36 \\
Custo alimentação/kg suíno produzido (R\$) & 2,76 & 2,84 & 2,61 \\
Índice de eficiência econômica & 94,60 & 91,90 & 100 \\
\hline
\end{tabular}

1- ração convencional; 2- ração convencional, com substituição de 30\% do milho pela cana-de-açúcar e 3ração convencional, com substituição de $30 \%$ do milho pela cana-de-açúcar e com os nutrientes corrigidos, exceto a energia.

"Preço dos ingredientes da ração adquiridos em fevereiro de 2012.

Quando se considera o custo de alimentação/kg de suíno produzido, o mesmo foi menor quando na utilização do tratamento 3 (30\% de cana-de-açúcar integral em substituição ao milho, com correção dos nutrientes), o que refletiu em um melhor índice de eficiência econômica em relação aos demais tratamentos (Tabela 5).

Em suínos na fase de terminação tardia recomenda-se a utilização de $30 \%$ de cana-de-açúcar integral, em substituição 
Rev. Bras. Saúde Prod. Anim., Salvador, v.13, n.4, p.1074-1083 out./dez., 2012 http://www.rbspa.ufba.br ISSN 15199940

ao milho, com correção dos nutrientes, pois promove melhor eficiência econômica.

\section{REFERÊNCIAS}

ARAÚJO, L.F.; JUNQUEIRA, O.M.; LOPES, E.L.; ARAÚJO, C.S.S.; ORTOLAN, J.H.; LAURENTIZ, A.C. Utilização de levedura desidratada (Saccharomyces cerevisiae) para leitões na fase inicial. Ciência Rural, v.36, n.5, p.156-1581, 2006.

ARRUDA, A.M.V.; FERNANDES, R.T.V.; SILVA, J.M.; LOPES, D.C. Avaliação morfo-histológica da mucosa intestinal de coelhos alimentados com diferentes níveis e fontes de fibra.

Revista Caatinga, v.21, n.2, p.1-11, 2008.

CASTRO JÚNIOR, F.G.; CAMARGO, J.C.M.; CASTRO, A.M.M.G.; BUDIÑO, F.E.L. Fibra na alimentação de suínos. Boletim da Indústria Animal, v.62, n.3, p.265-280, 2005.

CORDEIRO, M.D.; SOARES, R.T.R.N.; FERREIRA, R.A.; FONSECA, J.B.; DETMANN, E.; MERCADANTE, M.A. Cana-de-açúcar integral na alimentação de suínos em crescimento (30-60 kg). In: Revista Brasileira de Saúde e Produção Animal [Online], v.10, n.3, p.731-739, 2009.

FURTADO, P.A. Viabilidade econômica do uso de cana-de-açúcar na alimentação de suínos em fase de crescimento e terminação. Revista Porkworld, v.8, p.94-98, 2002.

GOMES, J.D.F.; FUKUSHIMA, R.S.; PUTRINO, S.M.; GROSSKLAUS, C.; LIMA, G.J.M.M. Efeitos do incremento da fibra em detergente neutro na dieta de suínos sobre a morfologia dos órgãos digestivos e não digestivos. Brazilian Journal of Veterinary Research and Animal Science, v.43, n.2, p.202-209, 2006.

GOMES, J.D.F.; PUTRINO, S.M.; GROSSKLAUS, C.; UTIYAMA, C.E.; OETTING, L.L.; SOUZA, L.W.O.; FUKUSHIMA, R.S.; FAGUNDES, A.C.A.; SOBRAL, P.J.A.; LIMA, C.G. Efeitos do incremento de fibra dietética sobre a digestibilidade, desempenho e características de carcaça: suíno em crescimento e terminação. Semina: Ciências Agrárias, v.28, n.3, p.483492. 2007.

HANSEN, I.K.; KNUDSEN, E.B.; EGGUM, B.O. Gastrointestinal impplications in the rat of wheat bran, oat bran and pea fiber. British Journal of Nutrition, v.68, p.451-459, 1992.

HEDEMANN, M.S.; ESKILDSEN, M.; LAERKE, H.N.; PEDERSEN, C.; LINDBERG, J.E.; LURINEM, P.; BACH KNUDSEN, K.E. Intestinal morphology and enzymatic activity in newly weaned pigs fed contrasting fiber concentrations and fiber properties. Journal of Animal Science, v.84, p.1375-1386, 2006.

LI, D.F.; NELSSEN, J.L.; REDDY, P.G.; BLECHA, F.; KLEMM, R.; GOODBAND, R.D. Transient hipersensitivity to soybean meal in the early-weaned pig. Journal of Animal Science, v. 68, p.1790-1799, 1990.

NERY, V.L.H.; SOARES, R.T.R.N.; CHIQUIERI, J. Desempenho e características de carcaça de suínos em terminação alimentados com rações contendo subprodutos de arroz.

Zootecnia Tropical, v.28, n.1, p.43-49, 2010. 
NOBLET, J.; LEGOFF, G. Effect of dietary fibre in the energy value of feeds for pigs. Animal Feed Science Technology, v.90, p.35-52, 2001.

NOBLET, J.; VAN MILGEN, J. Energy value of pig feeds: Effect of pig body weight and energy evaluation system. Journal of Animal Science, v.82, p.229-238, 2004. E. Suppl.

OETTING, L.L.; UTIYAMA, C.E.; GIANI, P.A.; RUIZ, U.S.; MIYADA, V.S. Efeitos de extratos vegetais e antimicrobianos sobre a digestibilidade aparente, morfometria e histologia intestinal de leitões recém-desmamados. Revista Brasileira de Zootecnia, v.35, n.4, p.1389-1397, 2006.

ROSTAGNO, H.S.; ALBINO, L.F.T.; DONZELE, J.L.; GOMES, P.C.; OLIVEIRA, R.F.; LOPES, D.C.; FERREIRA, A.S.; BARRETO, S.L.T. Tabelas Brasileiras para aves $\mathrm{e}$ suínos. 2ed. Viçosa: Universidade Federal de Viçosa, 2005. 186p.

SIEBRA, J.E.C.; LUDKE, M.C.M.M.; LUDKE, J.V.; BERTOL, T.M.; DUTRA JÚNIOR, W.M. Desempenho bioeconômico de suínos em crescimento e terminação alimentados com rações contendo farelo de coco. Revista Brasileira de Zootecnia, v.37, n.11, p.1996-2002, 2008.
VIEIRA, A.A.; BRAZ, J.M.; SANTOS, T.N.; AGONTINHO, S.P.; COSTA, A.D.; MATOS, E.S. Peso de órgãos internos de suínos alimentados com dietas contendo bagaço de cevada na fase de crescimento e abatidos com 100 kg. In: ZOOTEC, 2006, Recife, PE. Anais... Recife, PE: Associação Brasileira de Zootecnia, 2006.

WATANABE, P.H. Polpa cítrica na restrição alimentar qualitativa para suínos em terminação. 2007. 79p.

Dissertação (Mestrado em Zootecnia), Universidade Estadual Paulista, Jaboticabal.

WILFART, A.; MONTAGNE, L.; SIMMINS, P.H.; VAN MILGEN, J.; NOBLET, J. sites of nutrient digestion in growing pigs: effect of dietary fiber. Journal of Animal Science, v.85, p.976-983. 2007.

Data de recebimento: 15/07/2011

Data de aprovação: 05/12/2012 